\title{
Brinquedo terapêutico para crianças com Diabetes Mellitus tipo I: intervenções no domicílio
}

\author{
Therapeutic toy for children with Type I Diabetes Mellitus: Home interventions \\ Juguete terapéutico para niños con Diabetes Mellitus tipo I: intervenciones en el hogar
}

\author{
Letícia Roberta Pedrinho ${ }^{1}$ (C) \\ Bianca Machado Cruz Shibukawa ${ }^{1}$ (1) \\ Gabrieli Patricio Rissi ${ }^{1}$ (D) \\ Roberta Tognollo Borota Uema ${ }^{1}$ (c) \\ Maria de Fátima Garcia Lopes Merino ${ }^{1}$ (1) \\ leda Harumi Higarashi ${ }^{1}$ (D)
}

${ }^{1}$ Universidade Estadual de Maringá. Maringá, PR. Brasil.
Autor correspondente:

Bianca Machado Cruz Shibukawa.

E-mail: bih.cruuz@gmail.com

Recebido em 18/07/2020.

Aprovado em 10/11/2020.

DOl:https://doi.org/10.1590/2177-9465-EAN-2020-0278

\section{Resumo}

Objetivo: Descrever o uso do brinquedo terapêutico no cuidado domiciliar de crianças com Diabetes Mellitus tipo 1. Método: Estudo qualitativo do tipo Estudo de Caso, realizado com crianças com diagnóstico de Diabetes Mellitus tipo 1, residentes no interior do Paraná. Os dados foram coletados em 2018, por meio de entrevista com as mães, sessões de brinquedo terapêutico com as crianças e anotações no diário de campo. A análise dos dados foi realizada seguindo os preceitos da análise de conteúdo. Resultados: As crianças simularam situações cotidianas com o brinquedo terapêutico com naturalidade, evidenciando que cuidados com a glicemia e aplicação da insulina fazem parte da rotina. Contudo, demonstram sinais de insatisfação com a própria saúde, traçando comparações com crianças que não apresentam a doença e demonstrando suas angústias quando submetidas a procedimentos dolorosos. Conclusão: A utilização do brinquedo terapêutico permitiu a abertura de um canal efetivo de comunicação entre criança e profissional, possibilitando ao pesquisador compreender a percepção das crianças sobre sua condição de saúde e desenvolver orientações e cuidados direcionados. Implicações para a prática: Ao utilizar o brinquedo terapêutico, recurso de intervenção na assistência de enfermagem, como tecnologia de cuidado, amplia-se as possibilidades de atuação da enfermagem pediátrica, auxiliando crianças em condições crônicas.

Palavras-chave: Diabetes Mellitus tipo 1; Jogos e Brinquedos; Relatos de casos; Cuidado da criança; Enfermagem pediátrica.

\section{Abstract}

Objective: To describe the use of therapeutic toys in home care for children with type 1 Diabetes Mellitus. Method: Qualitative case study type study carried out with children diagnosed with type 1 Diabetes mellitus, residents of the interior of Paraná. Data were collected in 2018, through interviews with mothers, therapeutic play sessions with children and notes in the field diary. Data analysis was performed following the precepts of content analysis. Results: The children simulated everyday situations with the therapeutic toy naturally, showing that care with blood glucose and insulin application are part of the routine. However, they show signs of dissatisfaction with their own health, drawing comparisons with children who do not have the disease and demonstrating their distress when subjected to painful procedures. Conclusion: The use of therapeutic toys allowed the opening of an effective communication channel between child-professionals, enabling the researcher to understand the children's perception of their health condition, and to develop orientations and targeted care. Implications for practice: When using the therapeutic toy, a resource for intervention in nursing care, as a care technology, the possibilities of pediatric nursing work are expanded, helping children in chronic conditions.

Keywords: Diabetes Mellitus, Type 1; Play and Playthings; Case Reports; Child Care; Pediatric Nursing.

\section{Resumen}

Objetivo: Describir el uso de juguetes terapéuticos en el cuidado domiciliario de niños con Diabetes Mellitus tipo 1. Método: Estudio de caso tipo estudio cualitativo realizado con niños diagnosticados de Diabetes mellitus tipo 1, residentes del interior de Paraná. Los datos fueron recolectados en 2018, a través de entrevistas con madres, sesiones de juego terapéutico con niños y notas en el diario de campo. El análisis de datos se realizó siguiendo los preceptos del análisis de contenido. Resultados: Los niños simularon situaciones cotidianas con el juguete terapéutico de forma natural, demostrando que los cuidados con la aplicación de glucosa e insulina son parte de su rutina. Sin embargo, muestran signos de insatisfacción con su propia salud, haciendo comparaciones con niños que no padecen la enfermedad y demostrando su angustia al ser sometidos a procedimientos dolorosos. Conclusión: El uso de juguetes terapéuticos permitió la apertura de un canal de comunicación eficaz entre los niños y los profesionales, posibilitando al investigador comprender la percepción de los niños sobre su estado de salud, y desarrollar orientaciones y cuidados focalizados. Implicaciones para la práctica: Al utilizar el juguete terapéutico, recurso de intervención en el cuidado de enfermería, como tecnología asistencial, se amplian las posibilidades del trabajo de enfermería pediátrica y se presta ayuda a los niños en condiciones crónicas.

Palabras clave: Diabetes Mellitus Tipo 1; Juego e Implementos de Juego; Informes de Casos; Cuidado del Niño; Enfermería Pediátrica. 


\section{INTRODUÇÃO}

O Diabetes Mellitus tipo 1 (DM1), uma das doenças crônicas que mais afeta a população infanto-juvenil, tem mostrado aumento de sua incidência em todo o mundo. ${ }^{1}$ Muitas vezes, o DM1 se desenvolve em crianças que não possuem habilidades cognitivas e maturação emocional que permitam o planejamento e a tomada de decisões sobre os ajustes do seu regime terapêutico. ${ }^{1,2}$

Quando ocorre na infância, traz grandes repercussões no cotidiano familiar e no crescimento e desenvolvimento da criança. $\mathrm{O}$ adoecimento crônico infantil pode desencadear diversos conflitos familiares ante ao diagnóstico, como, por exemplo, o abandono do emprego, ocasionando desequilíbrio financeiro; redução ou interrupção dos momentos de lazer, sobrecarga do cuidador principal, e desestruturação familiar com repercussão negativa em toda a família. , $^{3,4}$

Trata-se de uma doença de difícil controle, propensa a diversas complicações agudas e crônicas. Portanto, após confirmação diagnóstica, faz-se necessário incorporar um tratamento rígido e permanente, a fim de estabelecer uma dieta alimentar adequada, prática controlada de atividade física e insulinoterapia. ${ }^{5} \mathrm{O}$ acesso restrito ao medicamento, a negligência no monitoramento da glicose e um estilo de vida pouco saudável, podem levar o paciente à morte. ${ }^{1}$

Destaca-se que as alterações na vida da criança são particularmente incômodas e contínuas, haja vista que o tratamento perpassa por restrições alimentares, injeções múltiplas de insulina, necessidade de atividade física regular e, ainda, pelo medo das possíveis complicações e mal-estar provocados pelos sintomas de hiper e hipoglicemia. ${ }^{6}$

A parceria integrada entre profissionais de saúde e pessoas vivendo com diabetes deve proteger a saúde e o bem-estar de todos os pacientes e suas famílias. ${ }^{1} \mathrm{~A}$ equipe multiprofissional deve incentivar a criança no tratamento do diabetes e incluir suas famílias, para que possam acompanhar e incentivar os filhos a manterem o seu cuidado. ${ }^{7}$

Os jogos e brinquedos podem funcionar como uma terapêutica de auxílio neste contexto, surgem como uma forma de imersão do profissional de saúde no universo do cuidado da criança com DM1, no qual, por meio de uma atividade natural da criança, ela é levada a expressar seus sentimentos e ansiedades diante da sua condição de saúde e a aliviar a tensão que sua realidade Ihe impõe. ${ }^{8}$

O brincar deve ser considerado pelo enfermeiro como a maneira mais adequada de se aproximar da criança, capaz de desenvolver uma empatia entre ambos, de ver e compreender o mundo com os olhos da criança e de estabelecer vínculos entre enfermeiro, criança e família.

Muitos trabalhos têm evidenciado a utilização do Brinquedo Terapêutico (BT) com crianças em ambiente hospitalar, no preparo de procedimentos dolorosos e cirurgias. , $^{9,10}$ No entanto, estudos sobre a aplicação do BT com DM1 em ambiente domiciliar são escassos.

O BT pode ser classificado em: dramático, quando tem como finalidade permitir que a criança exteriorize as experiências que tem dificuldade de verbalizar; capacitador das funções fisiológicas, utilizado na fase de readaptação física das funções fisiológicas dependendo da nova condição de vida da criança; e instrucional, quando objetiva preparar a criança para a realização de procedimentos terapêuticos. ${ }^{11}$

Diante de tais considerações, traduz-se a importância da realização de estudos que utilizem o BT como tecnologia de cuidado no enfrentamento do DM1 pelas crianças em ambiente domiciliar, avançando na abordagem investigativa deste agravo, para além dos períodos de descompensação da doença. Portanto, objetivou-se descrever a implementação do brinquedo terapêutico no cuidado domiciliar de crianças com Diabetes Mellitus tipo 1.

\section{MÉTODO}

A trajetória metodológica para este estudo se pautou na abordagem qualitativa, na modalidade estudo de caso, que consiste em coletar e analisar informações sobre determinado indivíduo, uma família, um grupo ou uma comunidade, a fim de estudar aspectos variados de sua vida, de acordo com o assunto da pesquisa. Ele é entendido como uma categoria de investigação que tem como objeto o estudo de uma unidade de forma aprofundada. ${ }^{12}$

O estudo foi ancorado na literatura disponível sobre o cuidado com o DM1, considerando-se que o uso da teoria nas pesquisas de estudos de casos sugere a utilização de algo que o sustente, podendo ser construído pelo próprio pesquisador, a partir de uma revisão de literatura ou pela construção de proposições teóricas que o conduzam no desenvolvimento do estudo. ${ }^{13}$

O estudo foi desenvolvido em domicílios com crianças diagnosticadas com DM1 há, no mínimo, três meses e que residiam em municípios pertencentes a uma Regional de Saúde do Estado do Paraná, composta por 25 municípios. A ampliação da área de abrangência de estudo para os municípios pertencentes à Regional de Saúde, e não apenas ao município de origem da pesquisadora e cidades circunvizinhas, se deu em função da dificuldade de captação de crianças que preenchessem os critérios de elegibilidade do estudo nesta área delimitada. Este aspecto pode denotar a deficiência no registro de dados desta clientela, e que não figuram nas estatísticas e registros oficiais dos serviços públicos de saúde.

Assim, para a captação dos participantes, primeiramente foi estabelecido contato com o Serviço Ambulatorial de Endocrinologia Pediátrica de referência para atendimento às crianças com DM1, pertencentes à regional de saúde, sendo fornecidos pelos profissionais os nomes das crianças que tinham idades para a inclusão no estudo. Em posse dos dados das crianças e de informações sobre os municípios de origem, os pesquisadores entraram em contato com os enfermeiros das UBSs de referência de cada criança, via telefone ou por mensagens de texto, a fim de confirmarem tais informações e de estabelecerem contato com as famílias.

Para delimitar a inclusão das crianças no estudo, definiu-se que essas deveriam estar cadastradas em uma UBS de cidades pertencentes à regional de saúde definida pelo estudo, pertencer 
ao grupo etário de crianças com idades entre dois e seis anos e ter mais de três meses de diagnóstico da doença.

Vale ressaltar que, dentro desse recorte etário proposto no estudo, as crianças já começam a apresentar capacidade de desenvolver o senso de domínio e autonomia, evoluindo para o desenvolvimento da autonomia e da iniciativa nas atividades, ${ }^{14}$ estando assim, aptas a desenvolver as atividades propostas pelo pesquisador.

A literatura sobre o diabete sustenta que,${ }^{15}$ para os pacientes com diagnóstico recente e seus cuidadores, a educação sobre a doença e sua aprendizagem inicial devem ocorrer desde o momento do diagnóstico e admissão na instituição de saúde até a alta hospitalar, recomendando uma consulta subsequente com a equipe interprofissional, em até um mês após a alta. Além disso, o acompanhamento profissional deve ser um processo em andamento ao longo da vida.

A inclusão dos participantes do estudo com o diagnóstico há pelo menos três meses buscou selecionar indivíduos com conhecimento sobre os cuidados com o DM1, e que haviam sido previamente orientados por profissionais de saúde competentes para realizarem os cuidados. Assim, considerou-se para essa seleção o fato de que, após esse período de convivência com a doença, as crianças do estudo, que foram diagnosticadas e permaneceram internadas por alguns dias, e seus cuidadores tiveram a oportunidade de receber orientações sobre os cuidados com o DM1 e desenvolvê-los no domicílio.

O critério de exclusão abarcou as crianças que estivessem em ambiente hospitalar ou passando por um quadro de descompensação glicêmica importante.

Assim, das cinco crianças selecionadas, foram recrutadas três que atendiam de forma plena aos critérios de elegibilidade estabelecidos, e que se mostraram adequadas à pesquisa segundo o método definido pelo autor. Ao todo, participaram do estudo seis indivíduos, sendo eles três crianças e suas mães.

Essa escolha ocorreu por se tratar de um estudo de caso do tipo coletivo, no qual o pesquisador não se concentra em um único caso para investigar um fenômeno, estendendo seu instrumento de estudo a vários casos, acreditando que seu estudo permitirá compreender melhor um conjunto ainda maior de casos. Assim, pode-se estabelecer o alcance dos resultados em outros contextos, dependendo das características dos casos selecionados. ${ }^{13}$

O primeiro contato com as famílias foi via telefone celular, pelo qual ocorreu a anuência em participar da pesquisa e agendou-se a primeira visita, de acordo com a disponibilidade dos participantes. Os encontros para a coleta de dados ocorreram no período de julho a outubro de 2018 , totalizando três visitas com cada uma das crianças e suas respectivas mães.

A coleta de dados se deu pela utilização de um roteiro de entrevista semiestruturado, formulado pela própria pesquisadora, pela utilização do BT e pelo registro das atividades em um diário de campo.

Por meio de entrevista semiestruturada com as mães, buscou-se caracterizar o ambiente, o contexto do adoecimento e a vivência da família e da criança frente ao diagnóstico do DM1. Foram levantadas informações como: idade e sexo da criança idade, escolaridade e ocupação dos pais; na existência de um cuidador principal da criança, sua idade e parentesco ou vínculo com o menor; renda familiar aproximada; se utilizava integralmente o SUS, plano de saúde privado ou realizava acompanhamento particular; tipo de parto; presença de intercorrências no período gestacional; peso e estatura ao nascer; escore de Apgar e dados sobre a amamentação e imunizações.

Informações sobre como ocorreu o diagnóstico do DM1 da criança, conhecimento prévio sobre a doença, orientações recebidas dos profissionais de saúde para os cuidados com a doença, acompanhamento ambulatorial e o histórico familiar de diabetes também foram investigadas.

Embora tenham sido coletadas pelo pesquisador as informações adicionais, anteriormente citadas, com o intuito de subsidiar a pesquisa, esses dados não serão aqui descritos por não serem objeto do presente estudo.

As intervenções com as crianças ocorreram por meio da aplicação do BT. Para tanto, previamente e no decorrer de toda a implementação do estudo, a pesquisadora se submeteu a reuniões e treinamentos junto ao grupo de pesquisa, tendo sido acompanhada à distância por uma doutoranda com ampla experiência na abordagem do uso de brinquedo terapêutico com crianças com diabetes. Ademais, para além disso, todos os cuidados éticos e operacionais preconizados para a aplicação do BT foram rigorosamente observados, com acolhimento de cada binômio mãe-filho no primeiro encontro, avaliações dialógicas a cada encontro, bem como respeito ao ritmo e disponibilidade individuais de cada participante. Tais cuidados redundaram na consolidação de um vínculo muito positivo entre pesquisadora e participantes, e na participação efetiva de cada um dos envolvidos.

Para realização das atividades foram disponibilizados objetos que consideravam a história pregressa de tratamento e internação da criança. Utilizou-se material de uso hospitalar como frasco de soro, equipos, água destilada, Sonda Foley, sonda gástrica, pacotes de gaze, luvas de procedimento, óculos de proteção, máscara e touca cirúrgica, atadura, tubo de coleta de exames, frascos de insulina, seringas, agulhas, canetas aplicadoras, lancetas, fita para glicemia, glicosímetro, algodão e álcool 70\%.

Além dos materiais utilizados na área hospitalar e dos insumos próprios para o cuidado com o diabetes, foram oferecidos para a criança outros tipos de brinquedos, com o objetivo de abarcar os demais cuidados como a alimentação e os exercícios físicos que são, também, pilares do cuidado com o DM1. ${ }^{15}$ Assim, foram oferecidos instrumentos que possibilitassem à criança dramatizar sua vivência com a doença e exteriorizar seus sentimentos, expressando-se livremente sobre o assunto. Dentre os materiais estavam um kit composto por papel, cola, canetas esferográficas e lápis de cor; bonecos de pano representando a família, enfermeira e médico; blocos de montar e brinquedos que remetessem a criança ao cotidiano doméstico, como alimentos, instrumentos de cozinha e de atividade física. 
Durante a aplicação do BT o pesquisador realizou, de forma concomitante, a observação das respostas e manifestações simbólicas da criança, com registro posterior de todas as informações em diário de campo. O uso do BT em domicílio permitiu ao pesquisador aproximar-se dos participantes da pesquisa em seu próprio ambiente, a fim de obter informações na ocorrência espontânea do fato. O registro em diário de campo, preenchido a cada visita, possibilitou a organização da atividade seguindo as etapas de planejamento, com checagem das ações implementadas e dos resultados alcançados.

O pesquisador, pelo uso do diário de campo busca assimilar detalhes que, ao serem compilados, congregam os diferentes momentos da pesquisa. Sua utilização demanda um uso sistemático que se estende desde o primeiro momento da ida ao campo até o final da investigação. ${ }^{16}$

O uso do BT se ancorou no Modelo de Cuidado de Enfermagem Cuidar Brincando, que propõe sua utilização como uma tecnologia de cuidado, imergindo no mundo das crianças, conhecendo a sua realidade e usando o brincar como uma forma de terapia, alicerçada teórica e metodologicamente. Esse modelo se estrutura em etapas: Acolhendo, com a finalidade de estabelecer vínculo entre criança e enfermeira; Brincando, na qual ocorre uma interação mais direta do enfermeiro com a criança e com o universo infantil, propiciando a percepção das dificuldades apresentadas no cuidado; Finalizando, relacionada efetivamente a uma situação de resolução dos déficits ou de percepção da necessidade de encaminhamento para outros profissionais. As sessões relativas a esse modelo de cuidado podem ser únicas ou múltiplas. ${ }^{17}$

No primeiro encontro com os participantes foram realizadas as orientações sobre o estudo, apresentado o Termo de Consentimento Livre e Esclarecido e a realizada a entrevista com as mães. Para as crianças, foram expostos os materiais e brinquedos que seriam, posteriormente, usados nas intervenções, a fim de que elas se familiarizassem com os objetos.

No segundo encontro, realizaram-se sessões com o Brinquedo Terapêutico Dramático (BTD) a fim de compreender a vivência das crianças com o DM1 e identificar os principais problemas de enfermagem, para posteriormente elaborar um plano de cuidado individual. Cada sessão durou, em média, 30 minutos.

A condução da sessão do BTD foi iniciada com a pergunta norteadora: "Vamos brincar de uma criança que tem diabetes?", adotando a seguinte sequência: 1 - A criança foi convidada a brincar com a pesquisadora, respeitando sua recusa; 2 - A criança recebeu informações sobre o tempo aproximado de duração da brincadeira e que os brinquedos seriam devolvidos ao final da sessão; 3 - Os brinquedos foram oferecidos sem identificação, permitindo à criança brincar livremente; 4 - A brincadeira não foi interrompida, direcionada ou agilizada; 5 - A pesquisadora participava conforme solicitação da criança, que procurou aprofundar a discussão acerca dos sentimentos verbalizados ou expressões apresentadas pela criança; 6 - As sessões foram gravadas em áudio e as observações foram registradas em diário de campo pela pesquisadora após o término da sessão.
7 - Quando o tempo de sessão estava próximo à finalização, a criança era avisada para que pudesse terminar a brincadeira.

Os dados foram analisados em concomitância com a coleta, considerando as falas das crianças e suas atitudes e expressões, descritas no diário de campo.

A análise dos dados seguiu as etapas da análise qualitativa de conteúdo na sua modalidade convencional, utilizada para descrever e promover o conhecimento e o entendimento sobre um determinado fenômeno cuja literatura é escassa, sendo que a codificação das categorias deriva diretamente dos dados, sem compromisso de comprovar estudos anteriores. ${ }^{11}$

A análise segue três passos: o primeiro consiste na leitura atenta do conteúdo oriundo da coleta dos dados e transcrições para sua posterior codificação; no segundo, a codificação é realizada identificando palavras, frases, temas ou conceitos que persistem nos dados e se destacam enquanto reveladores do fenômeno estudado; e no terceiro passo ocorre a categorização: cada código é retomado, relido, separado e classificado em grupos, segundo a similaridade das características conceituais, determinando as categorias temáticas. ${ }^{18}$

O estudo seguiu as recomendações estabelecidas pela Resolução n 466, de 12 de dezembro de 2012, e foi aprovado pelo Comitê de Ética em Pesquisa com Seres Humanos da Universidade Estadual de Maringá sob o parecer no 2.682 .522 e CAAE no 89210418.5.0000.0104 em maio de 2018. Os familiares das crianças que participaram do estudo assinaram em duas vias o termo de consentimento livre e esclarecido para menores.

\section{RESULTADOS}

A amostra do estudo foi composta por três crianças, as quais apresentavam entre 2 e 4 anos de idade. Para preservar a identificação das crianças participantes foram utilizadas referências a super-heróis e heroínas de histórias em quadrinhos, em analogia aos imensos desafios enfrentados por estes pequenos pacientes no cotidiano da doença crônica. Os dados serão expostos primeiramente a fim de caracterizar os participantes e posteriormente a categoria identificada após análise dos relatos e dos encontros.

Vale ressaltar que, embora as intervenções do estudo com a utilização do BT tenham sido realizadas com as crianças, as mães permaneceram em todos os momentos como suporte ao pesquisador, uma vez que elas eram as cuidadoras principais das crianças.

O "Homem-Aranha", tinha cinco anos no momento da pesquisa, estudante do primeiro ano do ensino fundamental, filho segundo de pais atualmente separados, mora com a mãe. O pai possui o ensino médio e atualmente está desempregado, e a mãe é esteticista. A renda mensal familiar é de aproximadamente dois salários mínimos.

Aos três anos de idade, diante de sintomas de polidipsia, polaciúria e perda de peso expressiva foi levado para consulta médica. Nesse primeiro atendimento, foi receitado antibiótico para amidalite e, devido à falta de diagnóstico de DM1 e da ausência de orientações sobre hiperglicemia, os sintomas pioraram, levando 
a criança ao estado de cetoacidose diabética (CAD). Ao ser conduzido a um Pronto Atendimento (PA) e com a realização do monitoramento glicêmico, foi realizado o diagnóstico de DM1, sendo encaminhado à Unidade de Terapia Intensiva (UTI).

Durante a internação na UTI, a mãe foi orientada sobre os cuidados com a doença e recebeu os encaminhamentos necessários para o seguimento ambulatorial com endocrinologista, nutricionista e psicólogo. A genitora também foi encaminhada para a Associação de Diabéticos na cidade de São Paulo (ADJ Diabetes), onde recebeu insumos e as principais instruções para o cuidado do seu filho. Atualmente, Homem-Aranha vive com a mãe e a irmã.

Em sua rotina, a glicemia capilar é realizada várias vezes ao dia, bem como a administração de insulina Protamina Neutra Hagerdorn (NPH) e Insulina Regular, por meio de seringa e agulha. Recentemente, passou a ter acompanhamento na rede privada, por meio de plano de saúde, oferecido pela avó paterna. Por estar ainda no período de carência do plano, quando necessário, utiliza o atendimento ambulatorial pelo Sistema Único de Saúde (SUS).

A alimentação foi orientada no momento do diagnóstico e a mãe faz adaptações, quando julga necessário, buscando auxílio na internet. Ele consome alimentos integrais e dietéticos, entretanto, também se alimenta da dieta normal da família. A criança teve duas hospitalizações, além da ocasião do diagnóstico, sendo uma por amidalite e, por precaução médica, permaneceu internado para observação e a segunda, por convulsões derivadas de hipoglicemia.

A segunda criança, chamada de Princesa Anna, tinha dois anos e frequentava a educação infantil de uma escola particular e morava com os pais que possuem terceiro grau completo. A mãe deixou o trabalho devido ao diagnóstico da filha e o pai trabalhava como autônomo, tendo uma renda familiar de aproximadamente cinco salários mínimos.

A criança foi diagnosticada três meses antes do desenvolvimento da pesquisa, quando passou a apresentar polidipsia, polaciúria (já estava desfraldada e retornou a utilizar), associada à polifagia. Em um primeiro momento, por estar fazendo uso de corticoides para o tratamento de asma, os sintomas foram associados, pela mãe, à droga utilizada. Em virtude da persistência e agravamento dos sintomas, a criança foi levada ao serviço médico e orientada pelo profissional de que os sintomas eram normais para a idade e que não havia motivos para preocupação. Após a consulta médica a mãe, não satisfeita com o diagnóstico, foi alertada pela enfermeira de que poderia ser DM1, no entanto, permaneceu sem o diagnóstico médico.

Não apresentando melhora do quadro, a criança foi levada no dia seguinte a uma Unidade Básica de Saúde (UBS) onde foi submetida ao exame de monitoramento glicêmico capilar, em jejum, no qual se constatou um valor de glicemia acima do normal esperado para idade, recebendo o diagnóstico e sendo encaminhada para tratamento especializado.

A criança permaneceu internada na UTI para observação e, posteriormente, encaminhada para a enfermaria pediátrica até a estabilização do quadro de CAD. Durante a hospitalização, a mãe recebeu as principais orientações sobre os cuidados com o DM1. Em um primeiro momento, foi utilizada a insulina regular e NPH, aplicadas por seringa e agulha e, posteriormente, iniciou a utilização de análogos de insulina ultrarrápidos e de ação prolongada, com o uso de caneta de aplicação.

Os cuidados relacionados à doença eram de total responsabilidade da mãe. A criança utilizava a insulina de três a quatro vezes ao dia, bem como um sensor externo adesivo (Libre), para verificação da glicemia, com o qual se elimina, em grande parte, a necessidade do procedimento invasivo tradicional. A criança não faz uso da rede pública de saúde, sendo o acompanhamento de sua doença realizado por meios particulares.

A criança apresentava taxas glicêmicas com poucas variações para a idade. O cardápio alimentar era organizado com o auxílio da médica endocrinologista e seguido, rigorosamente, pela mãe, que apresentava muito interesse no cuidado com a filha, além de buscar alternativas que ajudassem a melhorar sua qualidade de vida.

A terceira criança participante, denominada "Hulk", tinha quatro anos de idade, filho único, morava com os pais e frequentava educação infantil pública. Os pais possuíam ensino médio completo, o pai trabalhava como pedreiro e a mãe era do lar, com renda familiar mensal de aproximadamente dois salários mínimos.

O diagnóstico se deu em agosto de 2018, quando a criança começou a apresentar polidipsia, polaciúria, letargia e passou a se queixar de dor abdominal. A mãe refere que foi alertada por parentes da possibilidade de que os sintomas poderiam ser característicos de DM1, no entanto, a dor abdominal levou a mãe a procurar atendimento médico no PA da cidade.

Na consulta, diante do resultado do monitoramento glicêmico capilar, estabeleceu-se o diagnóstico de DM1. A criança foi encaminhada para serviço secundário de saúde e permaneceu hospitalizada em enfermaria pediátrica por cerca de uma semana, onde se iniciaram as condutas para o cuidado como aplicações de insulina e o monitoramento glicêmico.

Durante o internamento a mãe recebeu as primeiras orientações sobre a doença do filho, como a administração da insulina e o monitoramento glicêmico, entre outros. Hulk recebeu alta hospitalar utilizando os análogos de insulina ultrarrápidos e de ação prolongada, com o uso de caneta de aplicação.

Após a hospitalização, iniciou acompanhamento ambulatorial imediato, com endocrinologista pediátrico, recebendo os insumos para o cuidado ao DM1 pelo SUS e orientações sobre o regime alimentar. Os cuidados em domicílio eram compartilhados entre a mãe e avó de Hulk, entretanto a aplicação da insulina era realizada exclusivamente pela mãe.

A insulina era administrada de três a quatro vezes ao dia, assim como a realização do controle da glicemia capilar. A alimentação também era controlada pela mãe que, desde o diagnóstico, procurava adquirir alimentos que auxiliassem no controle glicêmico, embora outros alimentos também fossem consumidos pelos familiares. 
No processo de escolha dos personagens que as representariam, as crianças ficaram à vontade para eleger os que mais as agradassem, bem como os bonecos que representariam suas famílias e/ou seus cuidadores.

Neste momento do estudo, era disparada pelo pesquisador a seguinte questão:Vamos brincar de uma criança que tem diabetes?

No momento da apresentação da caixa de brinquedos, as crianças eram estimuladas a retirar, em primeiro lugar, o item que mais lhes despertasse a atenção.

Os relatos e observações oriundos desses momentos foram agrupados em uma categoria única denominada "Convivendo com DM1 na infância: um desafio diário", que engloba os cuidados com a alimentação, rotinas de cuidado com a doença e seu impacto na convivência em sociedade.

\section{Convivendo com DM1 na infância: um desafio diário}

Diante dos brinquedos apresentados para as crianças, em um primeiro momento, todas retiravam da caixa frutas e legumes, além de objetos de cozinha como panelas. Na medida em que manipulavam os objetos, os nominavam e simulavam o ato de se alimentar com eles:

Eu gosto muito de banana, mas só posso comer um pedacinho. Gosto muito de ovo também. As balinhas e bolachinhas, a mamãe não deixa comer. Mas eu não sei por que ela não deixa [...] (Princesa Anna).

Eu posso comer banana, maçã, melancia, laranja, de tudo eu posso comer. Posso comer chocolate também, mas antes eu não podia porque estava internado tomando soro (manipula o equipo de soro). Mas se eu comer muito, eu passo mal, fico tremendo (Hulk).

Posteriormente, passavam a interessar-se também em manipular materiais de uso hospitalar, tais como equipo de soro, seringas, luvas de procedimentos, glicosímetro, fita para realização da glicemia, bolas de algodão e as canetas de insulina, já que reconheciam estes objetos na sua rotina de cuidados.

Hulk pegava, além do seu personagem e os de sua família, uma boneca que representava a enfermeira, a qual era identificada em função de sua roupa branca. A criança descrevia que sempre ao acordar, a mamãe verificava sua glicemia, demonstrando com os bonecos tal procedimento. Brincava com o glicosímetro e, por vezes, esquecia-se de colocar a fita, retornando posteriormente e executando a atividade adequadamente. Com uma agulha, furava o dedo do boneco, demonstrando colocar o sangue no glicosímetro para, em seguida, usar a seringa de insulina, demonstrando a aplicação na região glútea do boneco:

\section{Eu não choro, eu não sinto nada (Hulk).}

A criança brincava com os bonecos que representavam ele e a enfermeira. Manipulava o glicosímetro com naturalidade e explicava como a mãe realizava o seu controle glicêmico e, em seguida, manipulava a caneta de insulina e demonstrava no boneco sua aplicação:

Primeiro, ela pega essa fitinha e coloca aqui (glicosímetro), depois fura meu dedinho, coloca aqui no aparelhinho e vê se eu preciso de insulina. Aí, se precisar, ela vai fazer em mim (Hulk).

A mamãe, depois de furar meu dedinho, pega essa caneta e conta aqui quanto tenho que tomar de insulina. Daí ela vem aqui (mostra a região glútea no boneco), e aplica. Eu não choro, eu não sinto nada (Hulk).

A princesa Anna indicava que a pesquisadora era a boneca que estava vestida de branco (enfermeira) e pegava o glicosímetro na mão, relatando que iríamos fazer o exame de glicemia.

Com a boneca nas mãos, buscava o algodão e o álcool para antissepsia. Passava o algodão no dedinho da boneca, colocava a fita no aparelho e verificava a glicemia. Em seguida, realizava o mesmo procedimento nos outros bonecos: mãe, pai, avó e enfermeira.

Quando questionada sobre quem realizava os procedimentos, ela respondia que era a mãe.

Esse negocinho faz "pique" no dedinho da princesa, e dói muito. Quem faz em mim é a mamãe. Eu não choro, mas dói. Depois faz a insulina e come uma fruta se precisar, mas só um pedacinho (Princesa Anna).

A criança explicava que tinha que comer uma fruta para não passar mal. Utilizava o equipo de soro para colocar na fossa cubital do boneco, que para ele representava o pai, dizendo que estava doente, pois tinha diabetes.

O Homem-Aranha começava a brincar com seu personagem e também com os outros que encontrava na caixa. Durante a brincadeira, lembrava-se de que precisava medicar seu boneco e ressaltava o desconforto que sentia em ter diabetes, enfatizando a dificuldade em não poder comer tudo que gostaria, como doce, por exemplo.

Ele demonstrava no boneco os locais de aplicação da insulina, contando que em alguns lugares de aplicação surgiam hematomas. Ele representava também a monitorização glicêmica nos dedinhos da mão do boneco, permitindo que o pesquisador realizasse o cuidado, sugerindo a região glútea do boneco, recusando a opção dada pela pesquisadora de que fosse realizado no braço do boneco. Dessa forma, a criança expressa a sua percepção sobre qual era o local de sua preferência, afirmando que no braço sentia dor. Ao longo da brincadeira, a criança afirmava ainda que, dentre os amigos da escola, somente ele tinha a doença.

O cotidiano referente ao monitoramento da glicemia e aplicação da insulina era relatado com certa tranquilidade, denotando um sentimento de aceitação, ainda que reconheça tratar-se de algo não comum a outras crianças de sua idade: 
[...] não dói nada, levo 60 mil furadinhas no dia, eu sou muito sensível, mas não choro, não durmo, eu sou diferente (Homem-Aranha).

Percebe-se, pelos relatos, que as crianças reproduziam no BT situações cotidianas no convívio com o DM1 com muita naturalidade, como se os cuidados em relação a glicemia e aplicação de insulina já fizessem parte de sua rotina. Ao mesmo tempo, durante essa reprodução da rotina, as crianças mencionaram críticas à sua condição, traçando comparações com outras crianças.

Odeio ter diabetes, porque eu não posso comer nada, não posso comer doce, só bolacha salgada. Na escola, ninguém tem diabetes. Onde a mamãe faz a insulina fica roxo (Homem-Aranha).

Embora as crianças deixassem transparecer em alguns momentos uma atitude de normalidade na vivência com o diabetes e que os procedimentos aos quais precisavam ser submetidas passaram a ser incorporados naturalmente à sua rotina de vida, sua dificuldade na adaptação era explicitada nas brincadeiras.

Elas demostravam a percepção de diferença da sua condição em relação a outras crianças quando, eventualmente, precisavam ser separadas de seus pares para algum procedimento relacionado ao cuidado com o diabetes, deixando de participar, por exemplo, de uma brincadeira na escola. Assim, os horários de intervalos nos pátios ou de refeições coletivas eram retratados, com o isolamento dos bonecos que os representavam, ora sendo submteidos a uma punção de controle de glicemia, ora em companhia e sob a vigilância de um adulto da escola, visando o não consumo de alimentos "proibidos".

As marcas e cicatrizes corporais devido à terapêutica invasiva como hematomas, lipodistrofias, sangramentos e lesões nas polpas digitais, possivelmente relacionadas às múltiplas punções para o monitoramento da glicemia e ao rodízio inadequado, ficaram fortemente retratados durante as brincadeiras das crianças com os bonecos. Estes elementos eram manifestados pelas crianças ao colocarem curativos sobre os locais das punções, ou ao demarcar estas regiões (regiões das mãos/dedos, pernas e abdômem) com canetinhas vermelhas.

\section{DISCUSSÃO}

A partir do conhecimento do cotidiano e dos desafios diários enfrentados pelas crianças diagnosticadas com DM1 diante dos procedimentos de controle da glicemia, foi possível observar seus hábitos, hesitações e sentimentos frente à cronicidade da doença. Nesse sentido, torna-se fundamental que o enfermeiro procure a melhor forma de comunicação com esse público alvo a fim de compreender e dialogar sobre o melhor caminho para o enfrentamento da doença e de sua terapêutica. ${ }^{8}$

O brinquedo terapêutico, nessa perspectiva, se encontra como uma ferramenta de comunicação essencial dos profissionais de enfermagem, pois permite a compreensão da realidade vivenciada pela criança e proporciona uma maneira lúdica de ensinar e readequar as práticas de verificação e controle glicêmico, além de encorajar o enfrentamento da doença. Essa ferramenta oportuniza também o esclarecimento de dúvidas e curiosidades, minimizando os temores e assimilando a inevitabilidade da realização desses procedimentos. ${ }^{8}$

As crianças do estudo, bem como suas famílias, embora compartilhem de experiências comuns no enfrentamento do DM1, possuem arranjos familiares, condições sociais e aspectos que precisam ser considerados. As demandas reveladas pelas crianças com DM1 e suas famílias são sempre singulares e requerem um cuidado individualizado, respeitando o tempo de aceitação da condição crônica e adaptação da família. Entretanto, deve-se ressaltar que a vivência com o DM1 não é uma constante, variando ao longo da vida, diretamente influenciada pelo estado físico e emocional da criança e do seu estágio de desenvolvimento. ${ }^{19}$

Deste modo, embora haja uma aceitação da realidade de viver com o diabetes, buscando uma condição de "quase normalidade", há momentos em que os aspectos negativos da doença e do tratamento ganham relevo, provocando tristeza, em função da necessidade do cuidado constante em relação a tudo que é vivenciado, como a adequação alimentar, convivência com a dor e com as limitações impostas em várias situações cotidianas. ${ }^{20}$

Atitudes de isolamento são bastente observadas em crianças e adolescentes com DM1 que podem levá-los a desenvolver baixa autoestima, comprometendo, por vezes, o desenvolvimento da mesma, dada a importância da socialização em todas as fases da infância, como estímulo ao amadurecimento físico e psicológico.

Estudos apontam que crianças com DM1 podem apresentar maior incidência de depressão, ansiedade, sofrimento psicológico e transtornos alimentares do que seus pares não acometidos pela doença. Isso porque tanto o agravo em si quanto seu tratamento podem exceder os recursos emocionais da criança para lidar com as demandas impostas pela doença. ${ }^{21,22}$

Até que atinja certo grau de maturidade, o que se dá por volta dos 8-11 anos, os cuidados essenciais com crianças com DM1 ficam sob responsabilidade de um adulto. ${ }^{14}$ Para manter a estabilidade dos níveis glicêmicos, o tratamento do diabetes impõe às crianças uma vida com maior disciplina. Considerando-se, então, a cronicidade da doença, que acompanhará a criança ao longo de toda a vida, torna-se imprescindível desenvolver estratégias em saúde que contribuam para o maior conhecimento sobre a doença e seus cuidados. ${ }^{15}$

Educar para o diabetes envolve, portanto, a necessidade de um processo de aprendizado individual e familiar, que promova um acompanhamento progressivo para o desenvolvimento da autonomia da criança para assumir seu próprio cuidado. ${ }^{23}$

O enfermeiro que acompanha a criança com DM1 deve buscar estratégias educativas que estimulem a criança a conhecer sua condição de doença e buscar o autocuidado. Desta forma, o BT pode e deve ser usado como adjuvante nesse processo. ${ }^{5,9}$

Os procedimentos técnicos para o cuidado com o DM1 podem ser reproduzidos sem que o indivíduo tenha real conhecimento 
das suas ações. Nesse contexto, embora reconhecendo a necessidade dos cuidados, muitas vezes as crianças parecem não conseguir avaliar com clareza os riscos e as complicações que a não realização correta dos procedimentos pode ocasionar para sua saúde, cabendo aos familiares orientá-las neste sentido. ${ }^{23}$

Cabe destacar que a compreensão sobre o tratamento promove o desenvolvimento de estratégias de enfrentamento adequadas, o que torna as crianças mais participativas, possibilitando a aquisição de habilidades para o autocuidado. ${ }^{24}$

A mãe se apresenta, de modo geral, como a cuidadora nas situações de doença dos filhos. A condição crônica da criança se torna uma situação desafiadora para a mãe, porém a confiança e capacidade de lidar com as adversidades surgem para ela ao longo do tempo de diagnóstico e pela prática cotidiana. ${ }^{25}$

Ela se torna, ainda, exemplo e referência a serem seguidos pela criança na sua vivência com a doença. A maneira e a importância com que a doença será tratada no convívio familiar influenciará, diretamente, a maneira com que a criança irá proceder com os cuidados ao longo do seu desenvolvimento e amadurecimento. ${ }^{26}$

A preocupação com a restrição alimentar e o controle dos carboidratos ficou explícita durante a brincadeira das crianças. Embora seja extemamente difícil para as famílias conviverem com as restrições alimentares a que as crianças com diabetes são submetidas, esse cuidado é imprescindível para evitar as descompensações glicêmicas e as complicações da doença a curto e longo prazos, constituindo um elemento capaz de gerar sentimentos de ambiguidade na criança, acerca dos cuidados que recebe. ${ }^{27}$

Assim, se por um lado a criança tem o desejo de comer doces, o que é comum na infância, por outro, há a necessidade premente de conter esse desejo, em função da doença. Portanto, diante do diagnóstico de DM1 e considerando-se que, invariavelmente, o comportamento alimentar é reflexo dos hábitos alimentares da família, faz-se necessário garantir orientação e apoio por ser esse o suporte para o cuidado voltado a esta condição da criança. 4,26,28

Foram demonstradas no estudo as dificuldades enfrentadas pelas crianças por sentirem-se diferentes de seus pares, em função de sua condição. As crianças vivenciam o conflito entre ser criança e fazer o que querem e não poder agir como outras crianças de sua idade, pela necessidade de adesão ao tratamento e pela dificuldade na aceitação das limitações impostas pela doença. ${ }^{29}$

Embora reconheçam que os cuidados são necessários para o controle glicêmico, muitas crianças consideram as injeções diárias de insulina e a verificação da glicemia capilar, além de dolorosos, atípicos e incompatíveis na sua vivência da infância. ${ }^{8}$

Constata-se que, quanto menor a idade da criança, mais naturalmente ela parece incorporar os procedimentos necessários para o controle da glicemia na sua rotina. No entanto, as sensações de dor e de tristeza são vivenciadas intensamente por ela, em função da sua condição. ${ }^{8}$

Considerando-se todas as questões que envolvem o adoecer da criança e sua convivência com a condição crônica, as intervenções educativas são essenciais de forma a abarcar os pilares do cuidado com o DM1 e a identificação dos fatores emocionais que possam gerar dificuldades no desenvolvimento do cuidado adequado para cada criança individualmente. ${ }^{15,20}$

\section{CONCLUSÕES E IMPLICAÇÕES PARA A PRÁTICA}

O estudo cumpriu para além do objetivo proposto em descrever o uso do brinquedo terapêutico no cuidado domiciliar de crianças com Diabetes Mellitus tipo I e contribuiu para a compreensão dessa experiência vivenciada pela criança. A utilização do BT como ferramenta de cuidado às crianças com DM1 permitiu a abertura de um canal de comunicação entre o profissional e as crianças fazendo com que elas expressassem seus sentimentos e vivências acerca de sua condição de saúde.

O enfermeiro, ao utiliar o BT como estratégia de comunicação e educação para crianças com diabetes, o transforma em uma tecnologia de cuidado, que amplia as possibilidades de atuação da enfermagem pediátrica com essa população, contribuindo para minimizar seu sofrimento, proporcionando um atendimento individualizado, identificando aspectos distintos de cada criança e os fatores que devem influenciar no seu desenvolvimento para, assim, prestar uma assistência mais humanizada.

A realização de sessões do BT no domicilio aponta para mais uma alternativa no trabalho de prevenção de agravos a ser realizada por enfermeiros na atenção primária à saúde, ampliando a qualidade da assistência de enfermagem à população pediátrica, em especial na doença crônica por meio do lúdico.

A limitação do estudo se configurou na dificuldade de captação de crianças com DM1, o que levou à necessidade de estender os limites geográficos da pesquisa para além do município e cidades circunvizinhas, abarcando a abrangência da 11 a regional de saúde do estado. Tal dificuldade pode ser decorrente da falta de um cadastro municipal e regional desta clientela, e que em última instância revela uma lacuna na atenção em saúde dessa população. Depreende-se, de tais achados, que esta clientela possa estar sendo negligenciada em seus cuidados, sendo privada de uma assistência sistematizada após o diagnóstico nos serviços de saúde.

\section{CONTRIBUIÇÕES DOS AUTORES}

Desenho do estudo. Letícia Roberta Pedrinho. leda Harumi Higarashi.

Coleta ou produção dos dados. Letícia Roberta Pedrinho.

Análise de dados. Letícia Roberta Pedrinho. leda Harumi Higarashi. Bianca Machado Cruz Shibukawa. Gabrieli Patricio Rissi. Roberta Tognollo Borota Uema. Maria de Fátima Garcia Lopes Merino.

Interpretação dos resultados. Letícia Roberta Pedrinho. leda Harumi Higarashi. Bianca Machado Cruz Shibukawa. Gabrieli Patricio Rissi. Roberta Tognollo Borota Uema. Maria de Fátima Garcia Lopes Merino. 
Redação e revisão crítica do manuscrito. Letícia Roberta Pedrinho. Bianca Machado Cruz Shibukawa. Gabrieli Patricio Rissi. Roberta Tognollo Borota Uema. Maria de Fátima Garcia Lopes Merino. leda Harumi Higarashi.

Aprovação da versão final do artigo. Letícia Roberta Pedrinho. Bianca Machado Cruz Shibukawa. Gabrieli Patricio Rissi. Roberta Tognollo Borota Uema. Maria de Fátima Garcia Lopes Merino. leda Harumi Higarashi.

Responsabilidade por todos os aspectos do conteúdo e a integridade do artigo publicado. Letícia Roberta Pedrinho. Bianca Machado Cruz Shibukawa. Gabrieli Patricio Rissi. Roberta Tognollo Borota Uema. Maria de Fátima Garcia Lopes Merino. leda Harumi Higarashi.

\section{EDITOR ASSOCIADO}

Aline Cristiane Okido

\section{REFERÊNCIAS}

1. International Diabetes Federation. Diabetes atlas. 9th ed. [Internet] Brussels: IDF; 2019 [citado 2020 jul 9]. Disponível em: https://www. diabetesatlas.org/en/

2. Katsarou A, Gudbjörnsdottir S, Rawshani A, Dabelea D, Bonifacio E, Anderson BJ et al. Type 1 diabetes mellitus. Nat Rev Dis Primers. 2017;3:17016. http://dx.doi.org/10.1038/nrdp.2017.16. PMid:28358037.

3. La Banca RO, Filietaz CFT, Tavares VR, Borba RIH. Compreendendo o ser adolescente com complicações do diabetes por meio do brinquedo terapêutico dramático. Rev. Norte Mineira de enferm. 2020;9(1):1-10. https://doi.org/10.46551/rnm23173092202090101.

4. Fornasini S, Miele F, Piras EM. The consequences of Type 1 diabetes onset on family life. An integrative review. J Child Fam Stud. 2020;29(5):146783. http://dx.doi.org/10.1007/s10826-019-01544-z.

5. Chiang JL, Maahs DM, Garvey KC, Hood KK, Laffel LM, Weinzimer $\mathrm{SA}$ et al. Type 1 diabetes in children and adolescents: a position statement by the American Diabetes Association. Diabetes Care. 2018;41(9):202644. http://dx.doi.org/10.2337/dci18-0023. PMid:30093549.

6. Oakley NJ, Kneale D, Mann M, Hilliar M, Tan J, Dayan C et al. Association between type 1 diabetes mellitus and educational attainment in childhood: a systematic review protocol. BMJ Open. 2018;8(8):e021893. http:// dx.doi.org/10.1136/bmjopen-2018-021893. PMid:30166302.

7. Feldman MA, Anderson LA, Shapiro JB, Jedraszko AM, Evans M, Weil LEG et al. Family-based interventions targeting improvements in health and family outcomes of children and adolescents with Type 1 diabetes. Curr Diab Rep. 2018;18(3):15. http://dx.doi.org/10.1007/s11892-0180981-9. PMid:29457190.

8. Pennafort VPDS, Queiroz MVO, Gomes ILV, Rocha MFF. Instructional therapeutic toy in the culture care of the child with diabetes type 1. Rev Bras Enferm. 2018;71(Suppl3):1334-42. http://dx.doi.org/10.1590/00347167-2017-0260. PMid:29972532.

9. láñez MJG, Cabrera MBM, Martos NS, Urquiza JLG, Román KV, Jiménez MJM et al. The use of children's stories in nursing care for the child: an integrative review. Health Care (Don Mills). 2020;8(239):1-12.

10. Aranha BF, Souza MA, Pedroso GER, Maia EBS, Melo LL. Using the instructional therapeutic play during admission of children to hospital: the perception of the family. Rev Gaúcha Enferm. 2020;41:e20180413. http://dx.doi.org/10.1590/1983-1447.2020.20180413. PMid:32348422.

11. Calegari T, Gimenes BP, Luz JH, Campos YA, Borba RI, Ribeiro CA Autist child in session of dramatic therapeutic play: Winnicott's analysis.
Rev. Soc. Bras. Enferm. Pediatras. 2018;18(1):43-8. http://dx.doi. org/10.31508/1676-3793201800007.

12. Yin RK. Case study research and applications: Design and methods Califórnia: Sage publications; 2017.

13. Lacerda MR, Costenaro RGS. Metodologias de pesquisa para a enfermagem e saúde: da teoria a prática. Porto Alegre: Moriá; 2016.

14. Hockenberry MJ, Wilson D. Wong. Fundamentos de enfermagem pediátrica. $9^{\mathrm{a}}$ ed. Rio de Janeiro: Elsevier; 2016.

15. Sociedade Brasileira de Diabetes. Diretrizes da Sociedade Brasileira de Diabetes 2019-2020. São Paulo: Clannad; 2019.

16. Minayo MCS, Deslandes SF, Gomes R. Pesquisa Social: teoria, método e criatividade. $28^{a}$ ed. Petrópolis: Vozes; 2009.

17. Rocha PK. Crianças vítimas de violência: cuidar brincando. Blumenau: Nova Letra; 2006

18. Renz SM, Carrington JM, Badger TA. Two strategies for qualitative content analysis: an intramethod approach to triangulation. Qual Health Res. 2018;28(5):824-31. http://dx.doi.org/10.1177/1049732317753586. PMid:29424274.

19. Vargas DM, Barbaresco AC, Steiner O, Silva CRLD. Um olhar psicanalítico sobre crianças e adolescentes com Diabetes Mellitus Tipo 1 e seus familiares. Rev Psicol Saúde. 2020;12(1);87-100. http:// dx.doi.org/10.20435/pssa.v12i1.858.

20. Moura FM. Vivências de crianças com Diabetes Mellitus tipo I [tese] João Pessoa (PB): Departamento de Enfermagem, Universidade Federal da Paraíba; 2016.

21. Delamater AM, Wit M, McDarby V, Malik J, Hilliard M, Northan E et al. ISPAD Clinical Practice Consensus Guidelines 2014. Psychological care of children and adolescentes with type 1 diabetes. Pediatr Diabetes. 2014 set;15(Suppl 20):232-44. http://dx.doi.org/10.1111/pedi.12191. PMid:25182317.

22. Silva RDM, Austregésilo SC, Ithamar L, Lima LS. Therapeutic play to prepare children for invasive procedures: a systematic review. J Pediatr (Rio J). 2017;93(1):6-16. http://dx.doi.org/10.1016/j.jped.2016.06.005 PMid:27485756.

23. Collet N, Batista AFMB, Nóbrega VM, Souza MHN, Fernandes LTB. Selfcare support for the management of type 1 diabetes during the transition from childhood to adolescence. Rev Esc Enferm USP. 2018;52(0):e03376. http://dx.doi.org/10.1590/s1980-220x2017038503376. PMid:30484485.

24. Moura FM, Costa Jr AL, Dantas MSA, Araújo GCB, Collet N. Playful intervention with chronically-ill children: promoting coping. Rev Gaúcha Enferm. 2014;35(2):86-92. http://dx.doi.org/10.1590/19831447.2014.02.41822. PMid:25158466.

25. Lindström C, Åman J, Norberg AL, Forssberg M, Anderzén-Carlsson A. "Mission Impossible"; the mothering of a child with Type 1 diabetes - from the perspective of mothers experiencing burnout. J Pediatr Nurs. 2017;36:149-56. http://dx.doi.org/10.1016/j.pedn.2017.06.002 PMid:28888496.

26. Gomes GC, Moreira MAJ, Silva CD, Mota MS, Nobre CMG, Rodrigues EF. Vivências do familiar frente ao diagnóstico de diabetes mellitus na criança/adolescente. J. Nurs. Health. 2019;9(1):e199108. http://dx.doi org/10.15210/jonah.v9i1.13393.

27. Tascini G, Berioli MG, Cerquiglini L, Santi E, Mancini G, Rogari F et al. Carbohydrate counting in children and adolescents with Type 1 diabetes. Nutrients. 2018;10(1):109. http://dx.doi.org/10.3390/nu10010109. PMid:29361766.

28. Queiroz MVO, Brito LMMC, Pennafort VPS, Bezerra FSM. Sensitizing children with diabetes to self-care: contributions to educational. Esc. Anna Nery Rev. Enferm. 2016;20(2):337-43. http://dx.doi.org/10.5935/14148145.20160046.

29. Sparapani VC, Borges ALV, Dantas IRO, Pan R, Nascimento LC Children with Type 1 Diabetes Mellitus and their friends: the influence of this interaction in the management of the disease. Rev. Latino-Am. Enfermagem; 2012;20(1):117-24. http://dx.doi.org/10.1590/S010411692012000100016. 